\title{
Magnetic resonance diffusion-weighted whole-body imaging (DWIBS) in the urinary bladder cancer diagnostics
}

\author{
Vladimir M. Popkov, M.L. Chekhonatskaya, Viktor V. Zuev, A.N. Ponukalin, Y.E. Nikolsky \\ Saratov State Medical University n.a. V.I. Razumovsky, Saratov, Russia
}

Accepted 20 July 2012.

Original Text in Russian (C) Popkov VM, Chekhonatskaya ML, Zuev VV, Ponukalin AN, Nikolsky YE, 2011, published in Saratov Journal of Medical Scientific Research 2011; 7(4): 941-946.

Abstract: The purpose of the article is to identify the most characteristic and significant changes of magnetic resonance indicators in patients with the urinary bladder cancer during diffusion-weighed whole-body imaging (DWIBS). Materials: From September 2009 till April 201198 patients have been examined: 61 (62.2\%) with morphologically verified bladder cancer and 37 (37.8\%) with cystitis. Results: The study has revealed that the sensitivity of DWIBS investigation in detecting bladder cancer is $98.36 \%$, specificity is 10.81 , and the efficacy is $65.38 \%$. Conclusions: DWIBS is an informative noninvasive method for screening diagnostics of bladder cancer, as well as for identificating suspicious areas of regional and distant metastases.

Keywords: urinary bladder cancer (UBC), diffusion magnetic resonance imaging (DMRT).

Cite as Popkov VM, Chekhonatskaya ML, Zuev VV, Ponukalin AN, Nikolsky YE. Magnetic resonance diffusion-weighted whole-body imaging (DWIBS) in the urinary bladder cancer diagnostics. Russian Open Medical Journal 2012; 1: 0210.

Correspondence to Viktor V. Zuev. Address: room 10, 12, Tulupnaya str., Saratov, 410031, Russia. Phone: +7-8452-281724.

E-mail: zuev.viktor.sgmu@gmail.com

\section{Introduction}

Primary neoplasms of the urinary bladder account for $2-6 \%$ of all tumours [1]. Due and adequate diagnostics of the urinary tract diseases still remains a complex and actual problem of ooncology [2].

Diffusion-weighted magnetic resonance tomography (DMRT) which provides functional information can be used in detection and characterization of pathological processes in the area of investigation including malignant tumours. The proposed Diffusion-Weighted Whole-Body Imaging with Background Body Signal Suppression (DWIBS) depicts the whole body volume diffusion. This new conception possesses unique characteristics, differs from standard DMRT and is capable to play an important role in screening diagnoistics of oncological diseases [3].

The aim of the study is to identify the most significant magnetic resonance (MR) iindicators and DWIBS investigation capabilities in diagnostics of the urinary bladder cancer (UBC).

\section{Material and Methods}

During the period from September 2009 till April 2011 there were examined 98 patients at the age of $45-81$ suspected of the urinary bladder cancer: 78 males (80\%) and 20 females (22\%). All the patients were admitted to the Scientific Research Institute of Clinical and Fundamental Uronephrology and Urological Clinic of Saratov State Medical University. 45 patients $(45.9 \%)$ complained of painful and frequent urination, 53 patients (54.1\%) demonstrated the signs of macrohematuria.

Depending on the results of histological investigation the patients were divided into two groups: the basic group consisting of 61 patients (62.2\%) with morphologically verified UBC (average age of $67 \pm 13$ years), and comparison group consisting of 37 patients (37.8\%) with cystitis (average age of $61 \pm 11$ years). Depending on the UBC stage in accordance with TNM clinical classification designed by International Anticancer Alliance in 2002 , the basic group was divided into four subgroups. Stage T1 of the pathological process was dfiagnosed in 33 patients $(54.1 \%)$, stage T2 - in 18 patients (29.5\%), stage T3 - in 7 patients (11.5\%), stage T4 - in 3 patients (4.9\%). All patients were performed cystoscopy and ultrasound scan.

MR investigation was performed on thre apparatus PHILIPS of 1.5 T magnetic field power with application of the "Body-array" roll for the body. The protocol of MR investigation consisted of two consequent steps. During the first step there was performed standard iinvestigation (T2WI, T1WI, T2WI with fatty tissue signal suppression in three mutually perpendicular planes and VISTA sequence in the axial plane) in order to detect preliminary tumour localization and visualize regional metastatic areas (Table 1).

Table 1. Features of standart MR investigation of pelvic organs

\begin{tabular}{lccccc}
\hline MR stage & MR plane & TR, $m s$ & TE, $m s$ & Fov, $m m$ & $\begin{array}{l}\text { Stage } \\
\text { duration }\end{array}$ \\
\hline T2WI & Sag, ax, cor & 3500 & 80 & 320 & $01: 38$ \\
T1WI & Sag, ax, cor & 900 & 7 & 320 & $02: 30$ \\
T2WI with & Sag, ax, cor & 3500 & 7 & 320 & $00: 56$ \\
f.t.s.s. & ax & 2000 & 200 & 130 & $01: 02$ \\
VISTA &
\end{tabular}

$\mathrm{T} 2 \mathrm{WI}$ with f.t.s.s. is $\mathrm{T} 2 \mathrm{WI}$ with fatty tissue signal suppression. 
For adequate urinary bladdrer fulfilment an hour prior MR investigation the patients had to drink $250-300 \mathrm{ml}$ of water and not to void urine for two hours before the investigation. With the catheter fixed in the urinary bladder directly prior the investigation $250-500 \mathrm{ml}$ of sterile solution were injected into the urinary bladder and the catheter was overpressed.

During the second step there was performed DWIBS investigation including complete $530 \mathrm{~mm}$ FOV in RL direction for complete imaging at simultaneous use of less FOV in FH direction for better resolution. Parameters of DWIBS investigation are: fat suppression STIR; b-value $\left(\mathrm{s} / \mathrm{mm}^{2}\right) 1.00$; direction of MPGs Phase, frequency and slice phase; frequency and slice; TR (ms) 10,205; TE (ms) 70; TI (ms) $180 \mathrm{NA}$; parallel imaging factor 2; halfscan factor 0.6; EPI factor 47; slice orientation Axial; no. of slices 60; slice thickness/gap (mm) 4/0; FOV (mm) 400; RFOV (\%) 70; matrix 160; scan percentage $70 \%$; actual voxel size $\left(\mathrm{mm}^{3}\right) \quad 2.5 \times 3.6 \times 4.0$; calculated voxel size $\left(\mathrm{mm}^{3}\right)$ 1.6x1.6x4.0; no. of signals averaged 10; scan time $7 \mathrm{~min} .8 \mathrm{~s}$.

DWIBS investigation resulted in three blocks of native axial scans visualizing the region from the upper third of the thigh up to the head with the possibility of native data processing and threedimensional inverted image constructing (Fig. 1).

\section{Results}

MR semiotics of the detected bladder wall changes in patients of the basic and comparison groups is given in Table 2 .

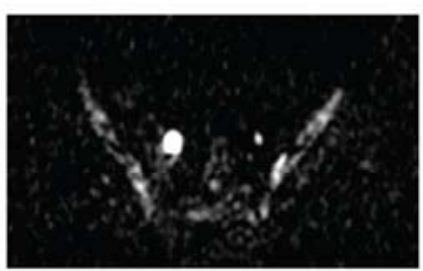

a

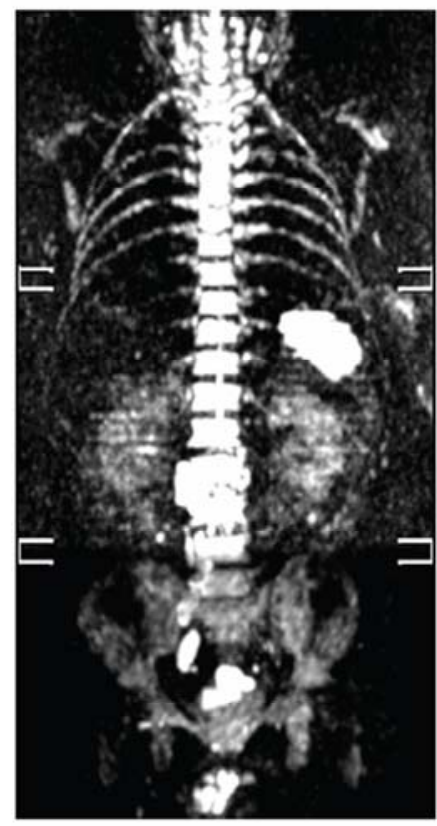

C

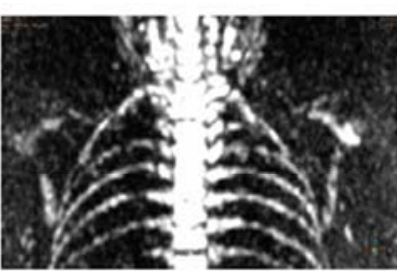

b

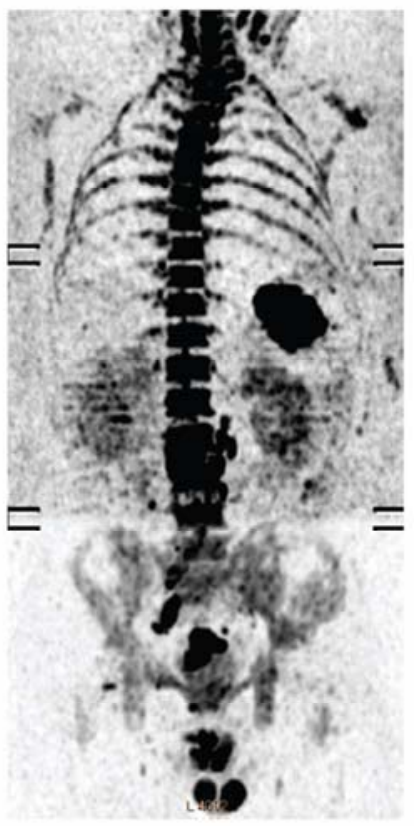

d
Figure 1. Sequence of formation DWIBS-image: native DWIBS-image in the axial plane (a), local 3D DWIBS-image (b), total 3D DWIBS-image (c), reversed total 3D DWIBS-image (d).
The analysis of the obtained data showed that independently of the pathological process stage lateral bladder walls were impaired more frequently; in stages $\mathrm{T} 1, \mathrm{~T} 3$ and $\mathrm{T} 4$ - predominantly the right bladder wall: in $48.4 \%, 57.1 \%$ and $66.6 \%$ of the patients respectively. Diffuse bladder walls impairment was detected in cystitis.

Frequency of ureter ostia involvement was comparable in patients with stages T1, T3 and T4. At the same time frequency of ureter ostia involvement in the pathological process in patients with stage $\mathrm{T} 2$ of UBC was significantly higher and reached $61.1 \%$. Independently of the stage there prevailed solitary bladder wall formations.

With advancing of the stage of tghe disease frequency of occurance of local bladder wall thickening in the area of the pathological formation increased: in $\mathrm{T} 1-51.5 \%$, in $\mathrm{T} 2-94.4 \%$, in T3 and T4 - 100\%. Change of MR bladder wall signal was detected in $42.4 \%$ of patients with stage $\mathrm{T} 1$, in $94.4 \%$ patients with stage $\mathrm{T} 2$, in $100 \%$ of patients with stages T3 and T4 of the disease. The same tendency was detected when evaluating the formation structure homogenity and enlarged regional lymphatic nodes detection frequency. Regularity of external bladder wall contours in stage T1 was $100 \%$. In stages T3 and T4 external bladder walls in all cases were irregular which corresponded to the verified stages of the pathological process. False signs of spread into the paravesical fat were detected in 6 patients (33.3\%) with stage T2. However, in routine MR investigation the possibility to evaluate distant changes in patients with UBC was lacking.

Later comparison and native $\mathrm{T} 2 \mathrm{WI}$ with high resolution and images of DWIBS investigation were carried out. Detection of areas with increased signal on native images and with decreased signal on three-dimensional inverted images was the criterion of DWIBS images evaluation. MR signal increase during native DWIBS investigation was normally detected from the brain structures, salivary glands, tonsils, spleen, gallbladder and small intestine (Fig. 2).

The data obtained during DWIBS investigation are given in Table 3. MR signal increase both from the pathological urinary bladder formation and regional and distal lymphatic nodes swas detected in 60 patients (98.4\%) of the basic group.

In the comparison group signal increase from the urinary bladder wall was not observed in 4 patients (10.8\%). During DWIBS investigation of the patients with stage $\mathrm{T} 2$ of $\mathrm{UBC}$ irregular external bladder wall contours in the area of the malformation (false MR sign of the formation spread into the paravesical fat) were detected in 1 patient (5.6\%), while during MR investigation in 6 patients (33.3\%) (Fig. 3).

The results of the carried out investigation demonstrate that DWIBS study sensitivity in detecting urinary bladder cancer is $98.4 \%$, specificity $-10.8 \%$, diagnostic effectiveness of the method $-65.4 \%$.

\section{Discussion}

For a long time diffusion magnetic resonance tomography (DMRT) was used only for investigation of the brain.

Extracranial DMRT was complicated by multiple artefacts from the movement and magnetic receptivity which resulted in the loss if diagnostic significance of the given investigation [2]. Increase of gradients and appearance of new multichannel rolls almost solved that problem, but up to the recent time extracranial DMRT was obligatorily carried out at the breath holding, because respirarory movements were the obstacles for DWI due to the shifts during the internal organs respiration [4]. 
Table 2. MR semiotics of UBC and cystitis in routine MR investigation of the pelvis organs

\begin{tabular}{|c|c|c|c|c|c|c|c|}
\hline \multirow[b]{2}{*}{ No. } & \multirow[b]{2}{*}{ MR sign } & \multirow[b]{2}{*}{ Scale } & \multicolumn{4}{|c|}{ UBC } & \multirow[b]{2}{*}{$\begin{array}{l}\text { Cystitis, } n(\%) \\
(n=37)\end{array}$} \\
\hline & & & $\begin{array}{c}\mathrm{T} 1, \mathrm{n}(\%) \\
(\mathrm{n}=33)\end{array}$ & $\begin{array}{c}T 2, n(\%) \\
(n=18)\end{array}$ & $\begin{array}{c}\text { T3, n (\%) } \\
(n=7)\end{array}$ & $\begin{array}{c}T 4, n(\%) \\
(n=3)\end{array}$ & \\
\hline \multirow[t]{5}{*}{1} & \multirow[t]{5}{*}{ What bladder walls were impaired? } & right & $16(48.4)$ & $6(33.3)$ & $4(57.1)$ & $2(66.7)$ & $0(0)$ \\
\hline & & left & $10(30.3)$ & $5(27.8)$ & $1(14.3)$ & $0(0)$ & $0(0)$ \\
\hline & & anterior & $2(6.1)$ & $2(11.1)$ & $0(0)$ & $1(33.3)$ & $0(0)$ \\
\hline & & posterior & $3(9.1)$ & $3(16.7)$ & $2(28.6)$ & $0(0)$ & $0(0)$ \\
\hline & & urocystic triangle & $3(9.1)$ & $2(11.1)$ & $0(0)$ & $0(0)$ & $0(0)$ \\
\hline \multirow[t]{4}{*}{2} & \multirow[t]{4}{*}{ Ureter ostia involvement } & no & $20(60.6)$ & 7 (38.9) & $4(57.1)$ & $2(66.7)$ & $37(100)$ \\
\hline & & right & $6(18.2)$ & $6(33.3)$ & $3(42.9)$ & $1(33.3)$ & $0(0)$ \\
\hline & & left & $7(21.2)$ & $4(22.2)$ & $0(0)$ & $0(0)$ & $0(0)$ \\
\hline & & both & $0(0)$ & $1(5.6)$ & $0(0)$ & $0(0)$ & $0(0)$ \\
\hline \multirow[t]{5}{*}{3} & \multirow[t]{5}{*}{ Number of bladder wall formations } & diffuse changes & $2(6.1)$ & $2(11.1)$ & $0(0)$ & $0(0)$ & $37(100)$ \\
\hline & & one thing & $23(69.7)$ & $15(83.3)$ & $6(85.7)$ & $3(100)$ & $0(0)$ \\
\hline & & two & $3(9.1)$ & $0(0)$ & $1(14.3)$ & $0(0)$ & $0(0)$ \\
\hline & & three & $3(9.1)$ & $0(0)$ & $0(0)$ & $0(0)$ & $0(0)$ \\
\hline & & more than three & $0(0)$ & $1(5.6)$ & $0(0)$ & $0(0)$ & $0(0)$ \\
\hline \multirow[t]{2}{*}{4} & \multirow[t]{2}{*}{ Bladder wall thickening } & yes & $17(51.5)$ & $17(94.4)$ & $7(100)$ & $3(100)$ & $37(100)$ \\
\hline & & no & $16(48.5)$ & $1(5.6)$ & $0(0)$ & $0(0)$ & $0(0)$ \\
\hline \multirow[t]{2}{*}{5} & \multirow[t]{2}{*}{ Change of MR signal from bladder wall } & yes & $14(42.4)$ & $17(94.4)$ & $7(100)$ & $3(100)$ & $37(100)$ \\
\hline & & no & $19(57.6)$ & $1(5.6)$ & $0(0)$ & $0(0)$ & $0(0)$ \\
\hline \multirow[t]{2}{*}{6} & \multirow[t]{2}{*}{ External contours of wall formations } & smooth & $33(100)$ & $12(66.7)$ & $0(0)$ & $0(0)$ & $0(0)$ \\
\hline & & rough & $0(0)$ & $6(33.3)$ & $7(100)$ & $3(100)$ & $0(0)$ \\
\hline \multirow[t]{3}{*}{7} & \multirow{3}{*}{$\begin{array}{l}\text { Regional lymph nodes (an increase of } \\
\text { over } 0.8 \mathrm{~cm} \text { ) }\end{array}$} & no & $33(100)$ & $11(61.1)$ & $3(42.9)$ & $1(33.3)$ & $35(94.6)$ \\
\hline & & single & $0(0)$ & 7 (38.9) & $4(57.1)$ & $2(66.7)$ & $2(5.41)$ \\
\hline & & conglomerate & $0(0)$ & $0(0)$ & $0(0)$ & $0(0)$ & $0(0)$ \\
\hline \multirow[t]{2}{*}{8} & \multirow{2}{*}{$\begin{array}{l}\text { Homogeneity of the structure of bladder } \\
\text { wall formations }\end{array}$} & yes & $28(84.8)$ & $10(55.6)$ & 3 (42.9) & $0(0)$ & 37 (100) \\
\hline & & no & $5(15.2)$ & $8(44.4)$ & $4(57.1)$ & $3(100)$ & $0(0)$ \\
\hline
\end{tabular}

Table 3. MR semiotics of UBC and cystitis in DWIBS investigation

\begin{tabular}{|c|c|c|c|c|c|c|c|}
\hline \multirow[b]{2}{*}{ No. } & \multirow[b]{2}{*}{ MR sign } & \multirow[b]{2}{*}{ Scale } & \multicolumn{4}{|c|}{ UBC } & \multirow{2}{*}{$\begin{array}{c}\text { Cystitis, } n(\%) \\
(n=37)\end{array}$} \\
\hline & & & $\begin{array}{c}T 1, n(\%) \\
(n=33)\end{array}$ & $\begin{array}{c}\mathrm{T} 2, \mathrm{n}(\%) \\
(\mathrm{n}=18)\end{array}$ & $\begin{array}{c}\text { T3, n (\%) } \\
(n=7)\end{array}$ & $\begin{array}{c}\text { T4, } n(\%) \\
(n=3)\end{array}$ & \\
\hline \multirow[t]{2}{*}{1} & MR signal increase from urinary bladder wall & yes & $32(97.0)$ & $18(100)$ & $7(100)$ & $3(100)$ & $33(89.2)$ \\
\hline & & no. & $1(3.0)$ & $0(0)$ & $0(0)$ & $0(0)$ & $4(10.8)$ \\
\hline \multirow[t]{2}{*}{2} & MR signal increase from regional lymph nodes & yes & $33(100)$ & $18(100)$ & $0(0)$ & $3(100)$ & $37(100)$ \\
\hline & & no & $0(0)$ & $0(0)$ & $7(100)$ & $0(0)$ & $0(0)$ \\
\hline \multirow[t]{2}{*}{3} & MR signal increase from distant lymph nodes & yes & $33(100)$ & $18(100)$ & $0(0)$ & $3(100)$ & $37(100)$ \\
\hline & & no & $0(0)$ & $0(0)$ & $7(100)$ & $0(0)$ & $0(0)$ \\
\hline \multirow[t]{2}{*}{4} & External contours of urinary bladder wall & smooth & $33(100)$ & $17(94.4)$ & $0(0)$ & $0(0)$ & $37(100)$ \\
\hline & & rough & $0(0)$ & $1(5.6)$ & $7(100)$ & $3(100)$ & $0(0)$ \\
\hline
\end{tabular}

T. Takahara et al. in 2004 reported about a new unique conception of the whole body DWI called "diffusion-weighted imaging of the whole body with the background body signal suppression" (DWIBS) [5]. Most researchers report that DWIBS investigation is a means for detecting lymphatic nodes independently of their histological composition $[5,6]$. The present study supports this viewpoint.

The results of the carried out study show that sensitivity of DWIBS investigation in detecting bladder cancer is high (98.4\%) but low specificity parameters (10.8\%) allow to judge rather about screening role of the given technique in complex diagnostics of the urinary bladder cancer.Rather significant results of the investigation, to our opinion, are relevant differences in detecting MR signs during DWIBS investigation and routine MRT of false spread of the bladder wall formation into the paravesical fat, which allows to differentiate stages $\mathrm{T} 2$ and $\mathrm{T} 3$ of the urinary bladder cancer.

Evaluation of the bladder neoplasm, possible regional and distant metastases allows to consider another way of potential DWIBS application - as the means of radiation- and chemotherapy effectiveness evaluation. DWIBS investigation makes it possible to visualize the signs and characteristics of the detected areas of alterated diffusion and to reveal pre-structural frunctional changes associated with the tumour [7]. 


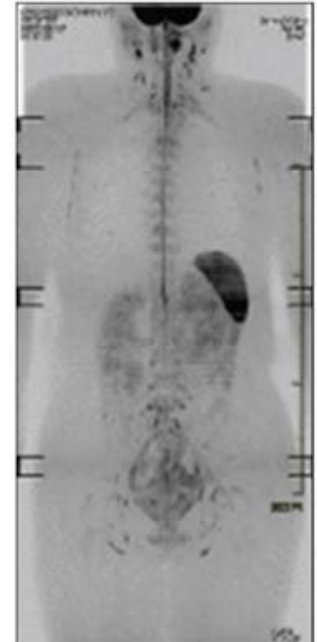

a

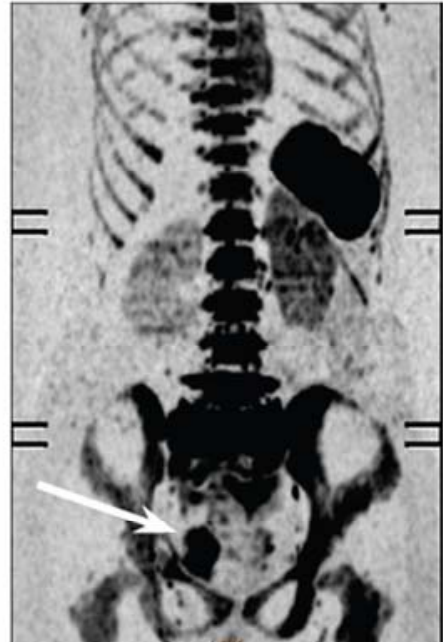

b
Figure 2. Reversed total 3D DWIBS-image in healthy subject (a) and UBC patients (b). The arrow indicates area of low power signal corresponding to UBC.

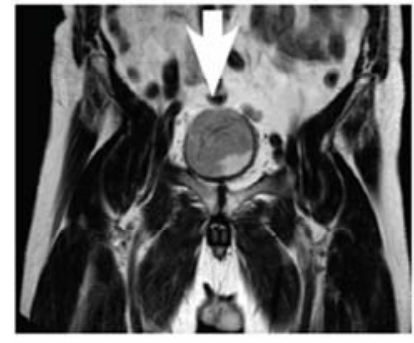

a

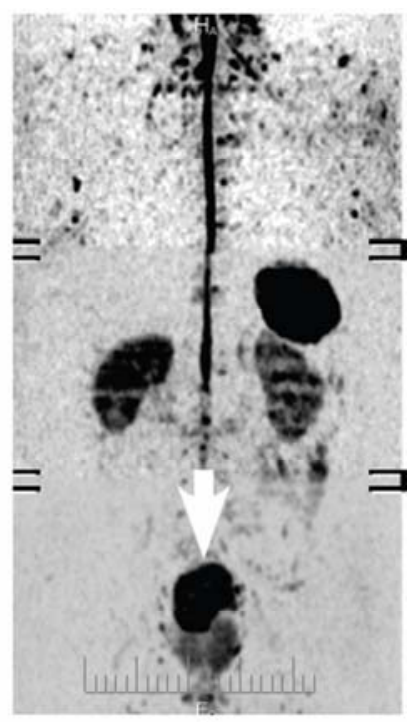

b
Figure 3. MR investigation: T2 WI-image (a) and DWIBS-image (b). The arrow indicates bladder wall formations, which has a homogeneous structure (T2 stage according TNM). External contours of wall formations is rough on T2 WI -image (signs distribution in perivesical tissue) and is smooth on DWIBS-image (no signs distribution in perivesical tissue).

\section{Conclusions}

DWIBS investigation in a number of cases verifies stages of the pathological process, i.e. allows to differentiate stages T2 and T3 of the urinary bladder cancer. Considering high sensitivity and low specificity of DWIBS investigation the described noninvasive informative technique could be used, basically, in screening diagnostics of UBC and in determining indications for expansive anatomical magnetic resonance tomography.

\section{Reference}

1. Wong-You-Cheong JJ, Woodward PJ, Manning MA, Sesterhenn IA. From the Archives of the AFIP: neoplasms of the urinary bladder: radiologic-pathologic correlation. Radiographics 2006; 26(2): 553-580 (PMID: 16549617) (doi: 10.1148/rg.262055172).

2. Ichikawa T, Haradome H, Hachiya J, Nitatori T, Araki T. Diffusionweighted MR imaging with single-shot echoplanar imaging in the upper abdomen: preliminary clinical experience in 61 patients. Abdom Imaging 1999; 24(5): 456-461 (doi: 10.1007/s002619900539) (PMID: 10475927).

3. Kwee TC, Takahara T, Ochiai R, Nievelstein RAJ, Luijten PR. Diffusionweighted whole-body imaging with background body signal suppression (DWIBS): features and potential applications in oncology. Eur Radiol 2008; 18(9): 1937-1952 (doi: 10.1007/s00330-008-0968-z) (PMCID: PMC2516183).

4. Low RN, Gurney J. Diffusion-weighted MRI (DWI) in the oncology patient: value of breathhold DWI compared to unenhanced and gadolinium-enhanced MRI. J Magn Reson Imaging 2007; 25(4): 848858 (PMID: 17335018) (doi: 10.1002/jmri.20864).

5. Takahara T, Imai Y, Yamashita T, Yasuda S, Nasu S, Van Cauteren M. Diffusion weighted whole body imaging with background body signal suppression (DWIBS): technical improvement using free breathing, STIR and high resolution 3D display. Radiat Med 2004; 22(4): 275-282 (PMID: 15468951).

6. Will O, Purkayastha S, Chan C, Athanasiou T, Darzi AW, Gedroyc W, Tekkis PP. Diagnostic precision of nanoparticle-enhanced MRI for lymphnode metastases: a meta-analysis. Lancet Oncol 2006; 7(1): 52 60 (PMID: 16389184) (doi: 10.1016/S1470-2045(05)70537-4).

7. Hamstra DA, Rehemtulla A, Ross BD. Diffusion magnetic resonance imaging: a biomarker for treatment response in oncology. J Clin Oncol 2007; 25(26): 4104-4109 (doi: 10.1200/JCO.2007.11.9610) (PMID: 17827460).

\section{Authors:}

Vladimir M. Popkov - MD, D.Sc., Head of Department of Urology, Rector of Saratov State Medical University n.a. V.I. Razumovsky, Saratov, Russia; M.L. Chekhonatskaya - MD, D.Sc., Professor, Head of Department of Roentgen Diagnostics, Saratov State Medical University n.a. V.I. Razumovsky, Saratov, Russia;

Viktor V. Zuev - MD, Senior Research Assistant, Department of Roentgen Diagnostics, Saratov State Medical University n.a. V.I. Razumovsky, Saratov, Russia;

A.N. Ponukalin - MD, PhD, Assistant Professor, Department of Urology, Saratov State Medical University n.a. V.I. Razumovsky, Saratov, Russia;

Y.E. Nikolsky - MD, Senior Research Assistant, Department of Roentgen Diagnostics, Saratov State Medical University n.a. V.I. Razumovsky, Saratov, Russia.

Conflict of interest: none declared. 